\title{
A medical malaise in hospital
}

\author{
John Roberts
}

PO Box 8098, Dar es Salaam, Tanzania John Roberts, MD, honorary lecturer, Muhimbili Medical Centre

BMF 1991;302:163-6
Walking around the grounds of St Bartholomew's Hospital, I was struck by the number of likenesses of Henry VIII. A huge portrait hangs in the donor's gallery in the north block; many smaller paintings adorn the walls; and over the main gate a statue of the robust monarch looks down at all who enter.

Henry is perhaps the most apt figure to adorn the hospital: it was he who closed down the hospitals in 1539 , thus creating the fraught relationship between British hospitals and their rulers that has lasted up till now.

Barts, 850 years old, and its descendent hospitals have managed to survive not only the marital problems of Henry VIII but also the liberal initiatives of David Lloyd George and Aneurin Bevan as well as the less liberal reformation led by Margaret Thatcher. Indeed, the greatest survivor of British hospitals seems to be the hospitals themselves.

Hospitals' doctors, too, have survived quite well under various governments. Bevan got his National Health Service after the second world war by promising hospital doctors two things: money and freedom. "I have stuffed their mouths with gold," he said of the bargain afterwards.'

Under the NHS consultants, the seniormost doctors in hospitals, have profited nicely. As the 1980 s closed their base salaries were about $£ 30000-£ 40000$ with merit awards-Bevan's "gold"-and private practice adding substantial supplements. (By comparison, a United States orthopaedic surgeon's median net salary is $£ 98000 .^{2}$ ) In fact, until 1989 , consultants seemed quite pleased with their niche in the NHS. Despite incomes below those of their United States colleagues, they had greater clinical freedom, jobs for life, respect from the public, and negligible threats from malpractice claims. When I visited English hospitals in 1987 hospital doctors were clearly happier than their American colleagues.

In 1991, however, the competition for unhappiest doctor may favour the British specialist, thanks largely to the government's white paper Working for Patients

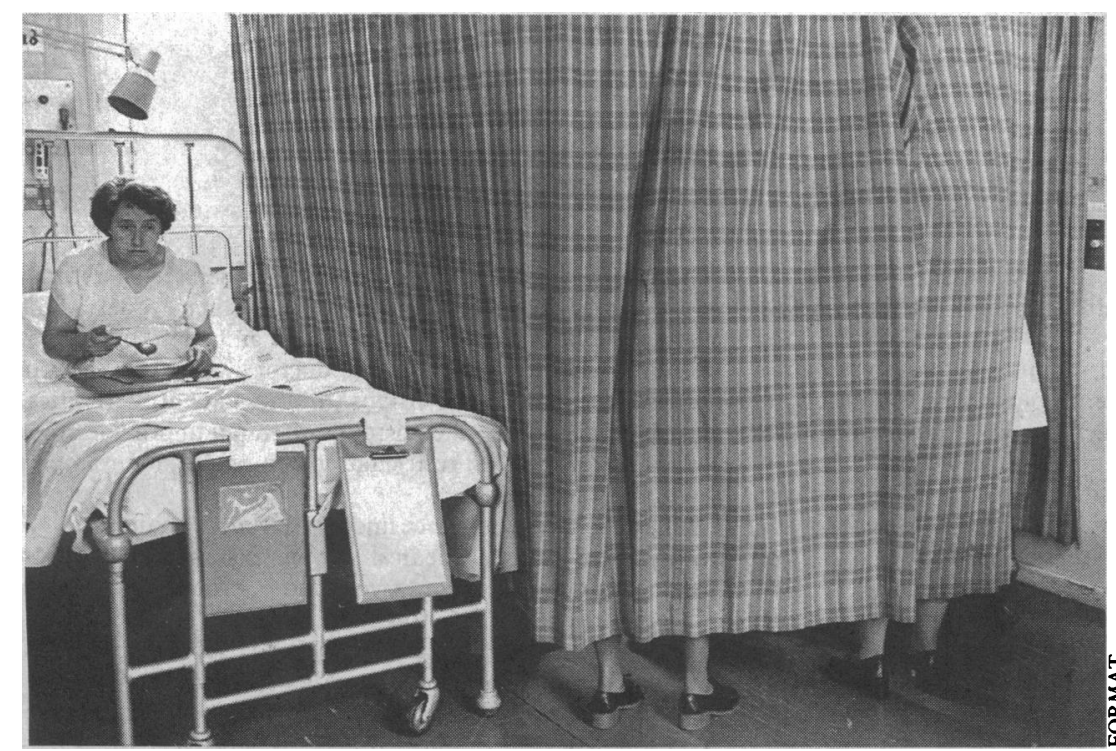

and the confusion and depression among doctors resulting from it. ${ }^{3}$ Several consultants told me the government has acted because of political ramifications arising from long waiting lists in the NHS. The government, speaking mostly through former health secretary Kenneth Clarke, has denied the charge. The hospital reforms arose, he said, "because doctors have not accounted for what they do. It is good to call oneself a 'healer,' but the public needs to know who is healed, what is cured, how it is done and how much it costs."

Last year hospital services cost the NHS about $£ 20000 \mathrm{~m}-72 \cdot 4 \%$ of the NHS budget. Private hospital services were $£ 1040 \mathrm{~m} .{ }^{4}$ Per person the British spend less than half on hospital care than the Americans. And while no one would say the British overspend on their hospitals plenty say they spend unwisely.

"In years past, I ordered tests and drugs for patients but I never once had to account for their costs," said a consultant physician at Queen's Medical Centre in Nottingham. Such behaviour may be medically defensible. But it is economically and politically reprehensible under the Conservative government. Working for Patients redefines much of the NHS: efficiency is a new goal; accountability and market economy are new means; and the key is the self governing trust.

Mr Clarke declared, "We're simply asking them to decide what they can do, then show us they can do it." Instead of following orders from above, self governing hospitals will negotiate their services with general practitioners and district health authorities. But a consultant summarised her colleagues' uncertainties: "We've been told we will be negotiating our services, but I don't know who I'll negotiate with, when we will negotiate, or what exactly we'll negotiate over." $\mathrm{Mr}$ Clarke was certain such confusion would clear up soon after 1 April.

\section{Getting by with less of most}

That the British hospital system is inefficient cannot be denied: hospitals are understaffed, overcluttered, and open warded. An American visitor wonders if patients don't get better just to get out as soon as possible. A young patient recalled blood stained cotton wool lying around beds, half empty intravenous bottles abandoned on window sills, and urine stains left unmopped in toilets. He quickly added, however, that the entire hospital staff was a dedicated lot who stayed in the NHS despite low salaries, gross understaffing, and difficult working conditions.

Indeed, after sitting in waiting rooms and canteens the visitor realises that values other than efficiency permeate British hospitals. They feel like churchesspiritual places with congregations who often reach into their pockets and help out with money when the government will not. (Much technology has been bought through the grace of such donors.) Courtesy and respect are important ingredients, as well. Consultants offer deference to the nurses and ask their permission to enter the wards.

Perhaps it is the particular mix of scant money, dedicated staff, and loyal public that makes British hospitals more judicious with technology. Less surgery 
is done. In the mid-1980s Aaron and Schwartz found the rate of coronary artery bypass grafts to be one sixth the rate in the United States. ${ }^{5}$ After correcting for population differences British surgeons performed half as many inguinal hernia repairs as United States surgeons in 1987 and one sixth as many prostate resections. On the other hand, British surgeons still perform $20 \%$ more tonsillectomies. ${ }^{46}$

Radiology is used more sparingly as well. Hospital patients get half as many radiographs as their American counterparts. Computed tomography comparisons are legion. Britain had $2 \cdot 4$ scanners per million people in 1988 , many of them bought by private fund raising campaigns. ${ }^{7}$ In a typical American state the rate exceeds 18 per million. (Even that number underestimates the true number of scanners in the United States: many radiologists have scanners in their offices and run mobile scanning services, none of which are reported in statistics (personal communication).) American patients with symptoms of stroke typically get a computed tomography brain scan on admission to hospital and four days later. British patients, if stable, are usually observed and placed on aspirin, with scanning done several days later, when ischaemic lesions become apparent.

\section{The waiting lists and the old NHS}

Critics say courtesy and frugal use of technology are not enough. The mass media have reported on children dying with heart defects after being turned away from hospitals that had closed beds to save money. Other reports have featured patients dying in accident and emergency waiting rooms or while waiting for ambulances. ${ }^{8 \cdot 11}$ All this media coverage has been summarised into the infamous hospital waiting list, the political unit of measure of NHS hospitals' inefficiency.
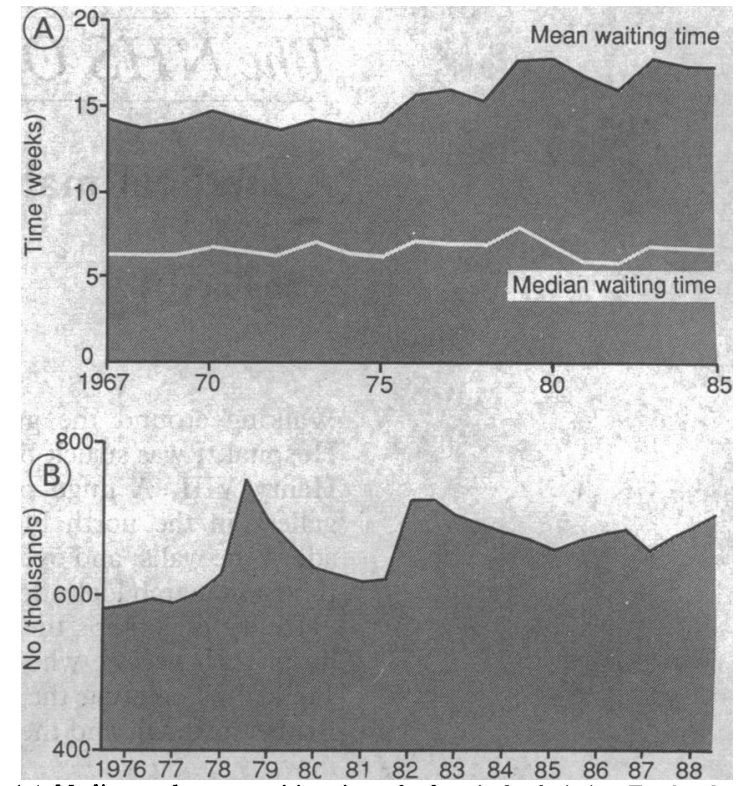
(a) Median and mean waiting times for hospital admission England and Wales 1967-81, England 1982-5. (b) Cases on NHS inpatient waiting lists England 1976-89

Between 600000 and 800000 Britons wait a mean of about four months for non-emergency operations such as hip replacements, hernia repairs, gall bladder removal, and cataract replacements. ${ }^{12}$ And, although median waiting times run at about five weeks, one surgeon acknowledged that he had patients waiting a year to see him, after which they would get put on a list to wait another year for their hip replacement.

Until the white paper was published waiting list politics ran a predictable course. When lists got long the public and press complained and the government

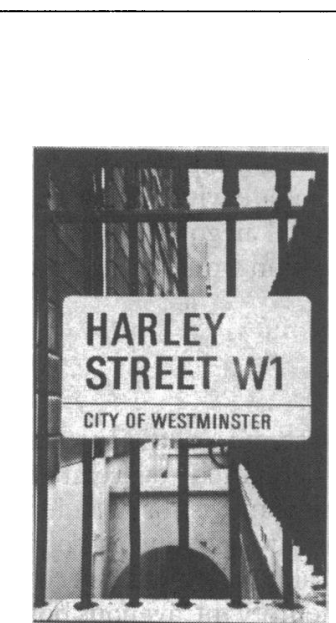

\section{Private medicine: the NHS's safety valve}

Harley Street in London is orderly, Victorian, and a bit understated for the lucrative symbol it represents. The only obvious signs of wealth are the glossy black doors and polished brass nameplates that list the scores of doctors that practise privately there.

Just over 1 in 10 Britons is covered by private medical insurance. (The comparable United States figure is about $70 \%$, though true comparisons are fraught with confounders: some United States patients carry multiple policies or are partly covered by government schemes.) Most live in or near London, and almost all are covered by one of three insurers: British United Provident Association (BUPA), Private Patients Plan, or Western Provident Association. Total spending by private insurers has been growing by $10-15 \%$ a year and last year topped $£ 1200 \mathrm{~m}$, about $4 \%$ of NHS spending.'

About $85 \%$ of London consultants do some private practice, most of them in surgical or invasive medical specialties, such as orthopaedics, obstetrics-gynaecology, and gastroenterology. A smaller percentage of those outside London practise privately. Actual salaries are difficult to estimate, since the NHS has decided that such matters are between doctors and their tax men.

In 1988, however, 15134 consultants practised in Britain. ${ }^{2}$ Private insurers reported paying to physicians and surgeons

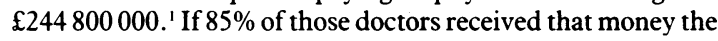
mean would be $£ 19030$ - an estimate that is necessarily low. A London surgeon, who refused to name his exact income, did say that his earnings from his $10 \%$ private practice well exceeded his NHS basic pay and merit award.

Private practice in Britain seems to deliver what American private practice promises: a free market for patients who can pay. Firstly, it provides an alternative for patients who prefer to avoid the NHS. Typical private subscribers-young and middle aged managers and professionals and their families- prefer to choose their doctors and do not wish to queue up for elective procedures. ${ }^{3}$ In addition, private abortion services give an option to women who are uncomfortable terminating their pregnancies through their general practitioners.

Top 10 procedures: $B U P A$ and NHS

\begin{tabular}{lcr}
\hline & \multicolumn{2}{c}{ Rank } \\
\cline { 2 - 3 } Procedure & BUPA & NHS \\
\hline Removal of impacted teeth & 1 & 9 \\
Upper gastrointestinal tract endoscopy & 2 & 13 \\
Dilatation and curettage (includes abortion) & 3 & 1 \\
Skin lesion excision & 4 & 22 \\
Total abdominal hysterectomy & 5 & 5 \\
Insertion of tympanic membrane tubes & 6 & 21 \\
Endoscopic examination of ovaries & 7 & 14 \\
Inguinal hernia repair & 8 & 7 \\
Cystoscopy & 9 & 3 \\
Breast lesion biopsy & 10 & 42 \\
\hline
\end{tabular}

Secondly, private medicine provides a service sometimes not delivered in the NHS: "To put it rather crudely," Sir Thomas Holmes Sellors once said, "In an [NHS] outpatient session the patient listens to the doctor, whereas in private practice the consultant listens to the patient." (Critics, however, say that private hospitals often fail to provide other basic medical services: resuscitation equipment, for example, is far from universal.)

Finally, private insurance injects a few more pounds into an underfunded national medical system. Insurance executives say the money pays for a few more procedures, which indirectly keeps NHS waiting lists shorter.

But critics, especially the Labour Party, say the opposite is true: consultants maintain long NHS waiting lists to sustain patients' demands for their private practices. The charge 
acted: hospital administrators were told, "Cut your lists-or else."

The quickest way to shrink a waiting list is to close beds. Under the topsy turvy economic rules of the NHS a full bed is costly; an empty bed is not. The more empty beds a hospital produces the more money can be saved and spent elsewhere-on patients waiting for new hips or hernia repairs. Patients still come in with infections and infarctions, however, and they must be admitted to hospital.

At Queen's Medical Centre an influenza outbreak last winter sent acutely ill patients to obstetric, orthopaedic, ear, nose, and throat, and general surgery wards, where nurses are not trained to deal with pneumonia and heart failure. Doctors' efficiency dropped as well, because their patients were spread over a hospital that is a quarter mile long on each side. At St Thomas's Hospital, a world famous institution just across the Thames from the Houses of Parliament and the Department of Health, bed closures left a third of its 1000 beds lying empty last autumn.

It is not only beds that cost money in the NHS: anything that is done for patients is money spent. For example, at St Thomas's money was pulled together to buy a lithotripter. But then it stood idle because it was too expensive to use-even though it would have prevented costlier surgery.

Long waiting lists and underused technology are truly foreign to a doctor from America, where a full bed and a busy lithotripter create profits for a hospital. But those examples only highlight the underlying differences between British and American hospitals and their doctors. Among others are the following.

No one oversees consultants-"Across very broad areas of NHS activity there is no direct assessment of the extent of cure or care or improvement achieved," according to one survey. ${ }^{13}$
Budgeting systems have operated to deter innovationAny money that has been saved during the year must be returned to the health authority, and spending across departments can be difficult. Planning becomes almost comical. Surgeons at Queen's Medical Centre tried to buy a laparoscope, but their department couldn't save the $£ 100000$ needed. Fortunately, delays in installing a new burglar alarm system left the hospital with $£ 300000$, a third of which bought the laparoscope.

Doctors are not attuned to money they spend- "Since I was never accountable, I never thought about what I was spending," said a general physician at Queen's. "But it is my moral responsibility to think about money, because NHS or not, patients do pay for what we do."

Hospitals have been run for doctors, not patients-An administrator described a district hospital that hired a surgeon with interests in neurosurgery. Though there was little local demand for such work, several beds were apportioned to it simply because of the surgeon's interest.

Consultants' appointments are virtually lifelong, and entrance into consultancy is closely guarded by both the profession and the government. "Lifetime appointments make us a terribly difficult group to manage," said a London surgeon.

But all is not bad in British hospitals. Frugal use of technology makes them safer places than American institutions, doctors argue. Some liabilities become assets as well when looked at from patients' perspectives.

Clinical freedom protects patients, as well as doctors. "No one can stand at the bedside and tell me how much I can spend to help a patient," said a surgical registrar. "No bureaucrat or government rule can come between us. My duty is simple: it is to my patient. You

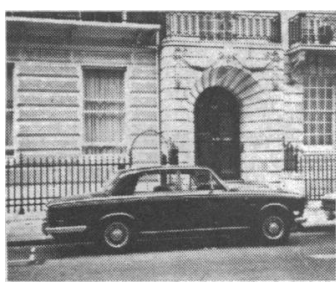

reflects topsy turvy NHS economics. "No industry, except the NHS, allows its central workers to go into business against their own company," said an administrator.

Consultants deny they are so savvy economically. A London surgeon recounted: "An American doctor said to me that we consultants are lazy, that if we 'got with it' we could work hard and make more money. We aren't entrepreneurs. And even in private practice we don't have to be because of the waiting lists. Being brash and undercutting the next person isn't in our national character." Two commissions have studied the relationship between longer NHS waiting lists and the growth of private practice. Neither found an association. ${ }^{3}$

Given that private medicine provides more options and shorter queues I was puzzled that only $10 \%$ of Britons are covered. One patient, a business executive who chose the NHS, explained: "Why go private? All I would get would be a

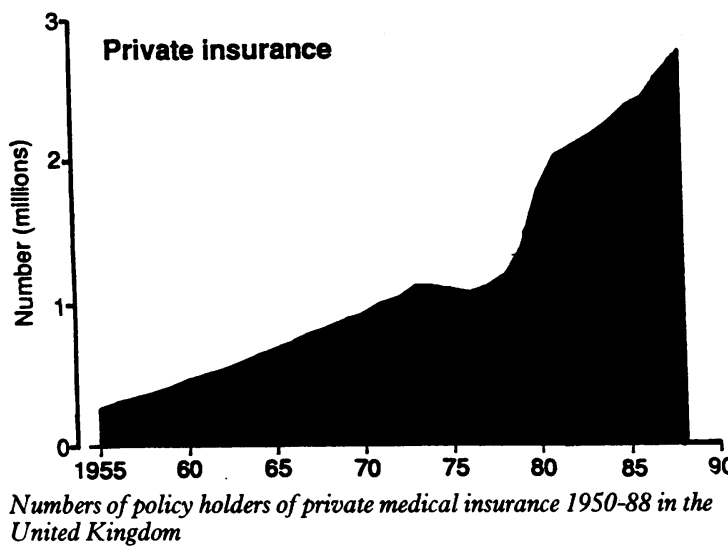

private room and a television. The care would be no better-perhaps worse" Said another patient: "The buildings are nicer, the queues are shorter, and the doctors have time to talk, though I think they're not so dedicated as NHS doctors."

The government makes no secret of its support for private medicine, however: under the white paper reforms private firms will be allowed to compete with NHS trusts. Government support drew American medical corporations to invest heavily in the mid-1980s. The number of British beds owned by United States corporations grew 10 -fold to about 2300 between 1979 and 1986 as United States investors predicted that Britain would become a medical haven for rich Arabian patients. Unfortunately, oil prices fell, and many Arabs chose French or German hospitals. On top of that medical competition in the United States grew severe, and the Americans were forced to retreat home to save their assets. By 1988 American owned beds had fallen to about 1600 .

Even with cautious doctors, however, the private sector probably will grow. British businesses are betting on it. Norwich Union last year invested $57 \mathrm{~m}$ in a new medical insurance plan, and Lloyds Bank and Leeds Permanent Building Society began offering plans last autumn.'

1 Laing W. Review of private healthcare 1989/90. London: Laing and Buisson, 1988.

Medical Manpower and Education Division, DHSS. Medical and dental prospects in the NHS in England and Wales in 1988. Health Trends 1989;21:158-76.

3 Higins J. The business of medicine: private health care in Britain. London: Macmillan Education, 1988.

4 Open University. Caring for health: dilemmas and prospects. Milton Keynes: Open University Press, 1985.

5 Woods R. Choice of private medical cover grows wider. Sunday Times 1990; Oct 7:4-11. 

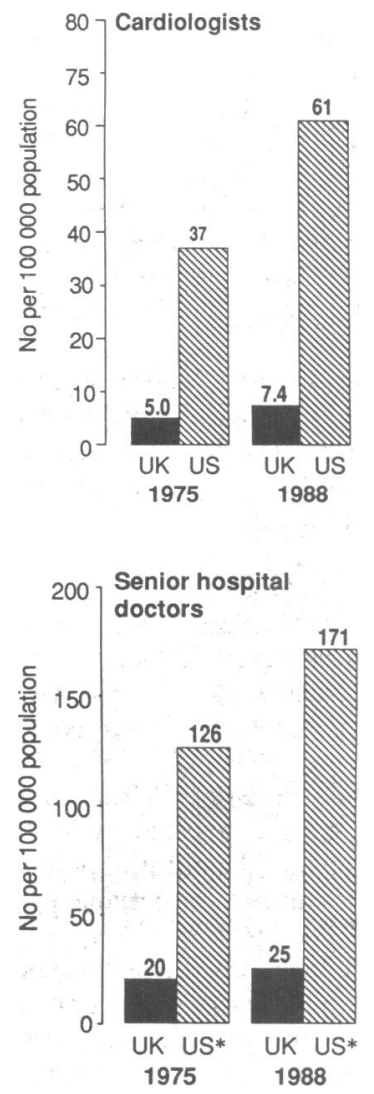

Supply of doctors in United Kingdom and United States. $\star$ In the United States about a third of senior doctors report engaging in primary care
Americans have insurers and stockholders to answer to, as well."

No incentive to overtreat exists - Profit does not follow procedures, as it does in America. An expatriate American summed up the difference: "In the States doctors get paid to do more. Here, they don't. I feel safer here."

Doctors influence hospitals' services-In the United States patient demand dictates what hospitals offer, so certain specialties grow (such as cardiology, whose "customers" are often middle aged professional men) and others shrink (such as long term psychiatry, whose customers mostly are on the dole). In Britain doctors' opinions have prevailed, so specialties such as oncology, geriatrics, and palliative care have prospered largely because doctors felt Britons needed those services.

\section{The new NHS: will it be improved?}

On 1 April all those arguments will be altered, though no one knows exactly how. The uncertainty leaves hospital doctors worried and filled with doubt.

Audit, said Mr Clarke, would give doctors a chance to see what they did well. Doctor-critics respond that the goal is laudable but that administrative costs will make audit extremely expensive, especially in the early years.

At the St Thomas's surgical directorate administrative costs have risen from $5 \%$ to $8 \%$ of total spending in 1990. (Administrative costs in America account for $23 \%$ of medical spending (Physicians for a National Health Plan, Boston, personal communication).)

Clinical audit has already conflicted with initiatives to cut surgical waiting lists at St Thomas's. Until recently doctors in surgical clinics saw four follow up patients for every new patient "in order to provide better teaching and assessment of what we were doing well and not so well," said surgical director Tony Young. Nowadays, the ratio is 1 to 1 so that new patients can get to surgery as soon as possible.

Older doctors seem especially worried about the ripple effects of self governing trusts. A Nottingham professor said, "Years ago if you were poor or lived outside London you got worse care. That's not true nowadays. But I worry that the trusts and free markets will inevitably lead back to that old system." Profit, he said, usually flows to the big cities.

Time is another concern. Already, consultants split their time among patient care, research, and teaching house officers and medical students. To add two other layers-planning and audit-will pull precious hours away from the first three. And, complained a geriatrician at Queen's, "Everything-including my timesoon will have a price on it. So in the academic community we shall no longer be able to give our time for extra teaching or consultation." Former health minister Clarke downplayed consultants' worry and doubt. He said, "We're trying to stop hospital doctors from being so detached from or at war with their administrators and to involve them in key management positions - particularly about the uses of resources. It does not mean the doctor is becoming an accountant, but he is becoming responsible for performance as a whole of his unit, not just carrying out the clinical work and walking away from the rest and moaning because some damned administrator and some bloody politician are failing to provide the resources he thinks he requires."

Whatever happens after 1 April the medical malaise will probably continue a while longer in hospitals.

"Uncertainty in politics creates caution in the NHS and among staff," said a physician. "Boldness and risk taking are unlikely because the government may change policy or a new government may be in within a year or two."

Indeed, looking back to the conflict between Henry VIII and the hospitals, one suspects the survivor of the current turmoil will not be the rulers. The hospitals survived Henry. They're proving more durable than Mrs Thatcher. And they'll survive her political descendants.

I Cartwright FF. A social history of medicine. London: Longman Group, 1977. Ebell ME. Choice of specialty: it's money that matters in the USA. JAMA $1988 ; 262: 1630-1$.

3 Secretaries of State for Health. Working for patients. London: HMSO, 1989.

4 Office of Health Economics. Compendium of health statistics. 7 th ed. Luton: White Crescent Press, 1989.

5 Aaron HJ, Schwartz WB. The painful prescription. Washington: Brookings Institution, 1984

6 National Center for Health Statistics. Health, United States 1988. Washington: US Government Printing Office, 1988

7 Hewer RL, Wood VA. Availability of computed tomography of the brain in the United Kingdom. BMf 1989;298:1219-20.

8 Dennier C. Boy faced two-hour wait for ambulance: father had to beg lift to hospital for son who needed scan. Oxford Mail 1987; Dec 11:7.

9 Mihill C. Funding cuts cause more pain for casualty patients. Guardian 1990; Oct 11:7.

10 Brindle D. Mentally ill convict dumped in casualty. Guardian 1990;Oct 5:3.

11 Brindle D. Hospital waiting lists 'inhuman.' Guardian 1990; Oct 18:2.

12 Laing W. Review of private healthcare 1989/90. London: Laing and Buisson, 1988.

13 Harrison S, Hunter DJ, Pollitt C. The dynamics of British health policy. London: Unwin Hyman, 1990.

\section{THE MEMOIR CLUB}

Twice I was asked to lead an investigation into clinics abroad offering unusual or ill supported cancer treatments but claiming to have cured many patients already given a hopeless prognosis. They were very different in the extent of their operations: one was run from a private house by a doctor with only one assistant and the other was an extensive affair employing a staff of over 100 . However, in other respects they had much in common: both presented a fascinating study of personalities and human relationships, neither had anything new of the slightest value to offer in the treatment of disease, both were producing results of which most hospitals would not have been proud. Both, lacking daily contact with others in the field, displayed a low standard of basic knowledge of the diseases they claimed to cure even though they saw large numbers of patients with the disorders they were treating. Both put forward claims for success with patients previously given up for dead, many of whom were found on examination to have suffered from a misdiagnosis, often made by someone else and uncritically accepted. Both had built their practices on kindly consideration for the emotional needs of patients desperately seeking hope and reassurance, most of whom had been badly handled before they arrived. Both presented their results by affirmation not by evidence, supported by anecdote and quoted opinion not by controlled trials. A long process of self delusion in those purveying "cancer cures" may lead to a feeling of persecution which increases with every challenge until the dawn of a growing realisation that all publicity, whether good or bad, enlarges their practice and therefore their prosperity. By such a process they can acquire an increasing belief in their own righteousness and learn that expressed antagonism towards orthodox medicine is profitable. Orthodox medicine, incidentally, is merely the best application of the current state of understanding backed by the most up-to-date techniques and is a constantly changing state of affairs, not at all the hidebound, unimaginative clinging to the past and to the rights of a close knit profession which it is sometimes said to be. Assessing the value of a new treatment seems to have been slow when it has proved successful, but there have been enough tragedies from the side effects of new drugs to discourage people from being too early in line for their expected benefits.

From Not a Moment to Lose by David Smithers. Published under the BMF's Memoir Club imprint. ISBN 072790278 4. Price: Inland £14.95; abroad $£ 17.50$. BMA members: Inland $£ 13.95$; abroad $£ 16.50$. 